\title{
Validation of the operational MSG-SEVIRI snow cover product over Austria
}

\author{
S. Surer ${ }^{1}$, J. Parajka ${ }^{2, *}$, and Z. Akyurek ${ }^{3}$ \\ ${ }^{1}$ Geodetic and Geographic Information Technologies, Middle East Technical University, Ankara, Turkey \\ ${ }^{2}$ Institute of Hydraulic Engineering and Water Resources Management, Vienna University of Technology, Vienna, Austria \\ ${ }^{3}$ Civil Eng. Dept., Middle East Technical University, Ankara, Turkey \\ * on leave from: Institute of Hydrology, Slovak Academy of Sciences, Liptovský Mikuláš, Slovakia
}

Correspondence to: S. Surer (serdarsurer@gmail.com)

Received: 12 September 2013 - Published in Hydrol. Earth Syst. Sci. Discuss.: 7 October 2013

Revised: 8 January 2014 - Accepted: 25 January 2014 - Published: 24 February 2014

\begin{abstract}
The objective of this study is to evaluate the mapping accuracy of the MSG-SEVIRI operational snow cover product over Austria. The SEVIRI instrument is aboard the geostationary Meteosat Second Generation (MSG) satellite. The snow cover product provides 32 images per day, with a relatively low spatial resolution of $5 \mathrm{~km}$ over Austria. The mapping accuracy is examined at 178 stations with daily snow depth observations and compared with the daily MODIS-combined (Terra + Aqua) snow cover product for the period April 2008-June 2012.

The results show that the 15 min temporal sampling allows a significant reduction of clouds in the snow cover product. The mean annual cloud coverage is less than $30 \%$ in Austria, as compared to $52 \%$ for the combined MODIS product. The mapping accuracy for cloud-free days is $89 \%$ as compared to $94 \%$ for MODIS. The largest mapping errors are found in regions with large topographical variability. The errors are noticeably larger at stations with elevations that differ greatly from those of the mean MSG-SEVIRI pixel elevations. The median of mapping accuracy for stations with absolute elevation difference less than $50 \mathrm{~m}$ and more than $500 \mathrm{~m}$ is 98.9 and $78.2 \%$, respectively. A comparison between the MSG-SEVIRI and MODIS products indicates an $83 \%$ overall agreement. The largest disagreements are found in Alpine valleys and flatland areas in the spring and winter months, respectively.
\end{abstract}

\section{Introduction}

Monitoring and modeling of snow characteristics is important for many hydrological applications, including snowmelt runoff forecasting and water resources assessment using a range of techniques (e.g., Blöschl and Kirnbauer, 1991; Blöschl et al., 1991; Nester et al., 2012). The large spatial variability of snow cover, particularly in mountains, limits the use of ground-based snow observations. Satellite imagery is thus an attractive alternative, as the resolution and availability does not depend much on the terrain characteristics (Parajka and Blöschl, 2008).

Recently, operational satellite products have become available that provide snow cover information at different spatial and temporal resolutions (Table 1). Table 1 indicates that most of the current products provide daily snow cover information at spatial resolutions ranging from $500 \mathrm{~m}$ to $5 \mathrm{~km}$. The numerous validation studies indicate that the satellite products have large snow mapping accuracy with respect to ground snow observations for cloud-free conditions, which varies between 69 and $94 \%$ in the winter seasons. The main limitation of existing optical platforms operating at a daily timescale is cloud coverage, which significantly reduces the availability of snow cover information. There are different approaches for cloud reduction, including space-time filtering (e.g., Parajka and Blöschl, 2008; Gafurov and Bárdossy, 2009; Hall et al., 2010, among others), but clouds are real and the accuracy of such approaches decreases with their efficiency to reduce clouds. 
Table 1. Summary of some existing operational satellite snow cover products.

\begin{tabular}{|c|c|c|c|c|c|}
\hline Snow cover product & Sensor & $\begin{array}{l}\text { Available } \\
\text { since }\end{array}$ & $\begin{array}{l}\text { Spatial } \\
\text { resolution }\end{array}$ & $\begin{array}{l}\text { Temporal } \\
\text { resolution }\end{array}$ & Mapping accuracy \\
\hline $\begin{array}{l}\text { NOHRSC/ } \\
+ \text { GOES }\end{array}$ & NOAA/AVHRR & 1986 & $1 \mathrm{~km}$ & $\begin{array}{l}\text { Daily } \\
\text { Barnett, 2003) }\end{array}$ & $76 \%$ (Klein and \\
\hline NOAA/NESDIS (IMS) & $\mathrm{GOES}+\mathrm{SSM} / \mathrm{I}$ & 1998 & $4 \mathrm{~km}$ & $\begin{array}{l}\text { Daily, } \\
\text { weekly }\end{array}$ & $\begin{array}{l}85 \% \text { (Romanov et al., } \\
2000) \\
<20 \% \text { (October), } \\
\sim 60 \% \text { (November), } \\
\sim 95 \% \text { (December), } \\
\sim 70 \% \text { (March) } \\
\text { (Brubaker et al., 2005) }\end{array}$ \\
\hline $\begin{array}{l}\text { MOD10A1, MYD10A1, } \\
\text { MOD10A2, MYD10A2, } \\
\text { MOD10C1, MYD10C1, } \\
\text { MOD10CM, MYD10CM }\end{array}$ & $\begin{array}{l}\text { MODIS- } \\
\text { Terra/Aqua }\end{array}$ & $2000 / 2002$ & $\begin{array}{l}500 \mathrm{~m} \\
-0.05^{\circ}\end{array}$ & $\begin{array}{l}\text { Daily, } \\
\text { 8-day, } \\
\text { monthly }\end{array}$ & $\begin{array}{l}\sim 94 \% \text { summary in Parajka } \\
\text { and Riggs, } 2007 \text { or } \\
\text { (see e.g., Hall } \\
\text { and Blöschl, 2012) }\end{array}$ \\
\hline HSAF (EUMETSAT) & MSG-SEVIRI & 2008 & $5 \mathrm{~km}$ & Daily & $\begin{array}{l}80 \% \text { compared to IMS } \\
\text { (Siljamo and } \\
\text { Hyvärinen, 2011); } \\
69-81 \% \text { in winter } \\
\text { months (Surer and } \\
\text { Akyurek, 2012) }\end{array}$ \\
\hline
\end{tabular}

An alternative to the space-time filtering of daily products is to merge satellite images obtained at higher temporal resolution. The new generation of MSG-SEVIRI product provides snow cover information at 15 min temporal resolution for the whole Northern Hemisphere. The preliminary assessment of data from one snow season over eastern Turkey (Surer and Akyurek, 2012) indicates that the merging of 32 consecutive images per day enables a $37 \%$ reduction of clouds in comparison to the MODIS daily product, and improves the mapping of regional snow-cover extent over mountainous areas.

The main objective of this study is to assess the accuracy of the new MSG-SEVIRI snow cover product over Austria for the period 2008-2012. The spatial and temporal variability in mapping accuracy is examined for a large number of meteorological stations observing snow depth and is evaluated against combined MODIS snow cover product. Austria is an ideal test bed for such an assessment, as it allows evaluating the mapping accuracy in different altitudinal zones ranging from the lowlands to the high Alpine environment. The MSG SEVIRI snow product has been produced operationally within the HSAF project funded by EUMETSAT. The validation studies composed of ground observation comparisons with satellite snow product have been performed on mountainous areas of Europe (HSAF, 2011). The idea in this study is to extend the test sites in order to evaluate the MSG SEVIRI snow product and perform detailed validation studies.

\section{MSG-SEVIRI snow cover product}

The Spinning Enhanced Visible and Infrared Imager (SEVIRI) is an optical imaging radiometer mounted aboard the geostationary Meteosat Second Generation (MSG) satellite operated by EUMETSAT. MSG-SEVIRI provides continuous imaging of the earth in 12 spectral channels with a repeat cycle of $15 \mathrm{~min}$. The imaging spatial resolution is $3 \mathrm{~km}$ at sub-satellite point (Aminou, 2002) and degrades to $5 \mathrm{~km}$ over Europe.

The snow cover mapping is based on a multi-channel retrieval algorithm. It exploits the high reflectivity of snow in the visible spectrum and the low reflectivity at shorter wavelengths. The snow cover retrieval algorithm differs for flat and mountainous regions. Considering the different characteristics of snow for mountainous and flat areas, two different algorithms are used in producing the snow products for flat and mountainous areas, and then the products are merged to have a single snow product. In flat regions, the algorithm utilizes the top-of-atmosphere radiance of six SEVIRI channels $(0.6,0.8,1.6,3.9,10.8$ and $12.0 \mu \mathrm{m})$ and brightness temperatures of three channels $(3.9,10.8$, and $12.0 \mu \mathrm{m})$. The snow recognition is based on the snow cover classification (Siljamo and Hyvarinen, 2011). The cloud-snow discrimination for flatlands relies on the cloud mask (CMa) provided by the Nowcasting and Very Short Range Forecasting Project (NWCSAF, 2007). In this product clouds are classified only into two classes (cloud contaminated and cloud filled).

In the mountains, the snow recognition algorithm uses the snow index $(\mathrm{SI})$, which relates $0.6 \mu \mathrm{m}(0.56-0.71 \mu \mathrm{m})$ and 
Table 2. Number of meteorological stations in different elevation zones.

\begin{tabular}{lcccccc}
\hline $\begin{array}{l}\text { Elevation } \\
\text { zone (m a.s.1.) }\end{array}$ & $0-500$ & $500-1000$ & $1000-1500$ & $1500-2000$ & $2000-2500$ & $2500-3109$ \\
\hline Number of stations & 59 & 78 & 29 & 6 & 4 & 2 \\
\hline
\end{tabular}

$1.6 \mu \mathrm{m}(1.5-1.78 \mu \mathrm{m})$ SEVIRI channels. The used snow index is obtained by dividing the bands NIR1.6 to VIS0.6. The pixels having NIR1.6/VIS0.6 values lower than a fixed threshold value of 0.6 were collected. The cloud-snow discrimination is based on the CMa and cloud type (CT) product of the NWCSAF. The CT product has 15 different cloud types, which allow more robust cloud recognition (Surer, 2008). Both algorithms use sun zenith angle for discarding the low-illuminated areas, and land surface temperature values for covering all cold pixels below freezing point (Romanov et al., 2003). The main difference in the algorithms is the location of the samples collected for developing the thresholding method, and the cloud-snow discrimination applied in the retrieval. A detailed description of the MSG-SEVIRI snow algorithm is presented in the Algorithm Theoretical Basis Document (HSAF, 2010).

The definition of the mountainous areas is based on the mean altitude and standard deviation of the slope within $5 \mathrm{~km}$ $\times 5 \mathrm{~km}$ pixels (Lahtinen et al., 2009). The area is defined to be mountainous if the mean altitude in the particular mesh exceeds $1000 \mathrm{~m}$ or the mean altitude in the mesh exceeds $700 \mathrm{~m}$, and the standard deviation of the slope is greater than $2^{\circ}$ or the mean altitude variation (the difference between the maximum and minimum altitude in the particular mesh) exceeds $800 \mathrm{~m}$ and the mean altitude exceeds $500 \mathrm{~m}$.

Daily snow cover maps are derived from 32 images per day, blending data from 08:00-15:45 UTC +2 . Snow cover is mapped when there are at least 4 hits of snow recognition in a day. The final snow cover product, which is merged at Finnish Meteorological Institute, has snow, land, cloud, water and unclassified classes. An example map for Europe is presented in Fig. 1.

\section{Study area and snow cover data}

This paper evaluates the accuracy of snow cover images over Austria. Austria is located in the temperate climate zone, where the Alps act as a dominant barrier between continental climate in the north and the meridional circulation from the Adriatic Sea in the south. Elevations range from $115 \mathrm{~m}$ in the flatlands to more than $3700 \mathrm{~m}$ in the mountains (Fig. 2). Mean annual precipitation varies between $400 \mathrm{~mm}$ in the eastern flatlands and almost $3000 \mathrm{~mm}$ in the western part of the Alps. The mountainous parts of Austria are covered by snow for several months a year (Parajka and Blöschl, 2006), while the flatlands are characterized by warm and dry summers and cold winters without significant snowfall. Land

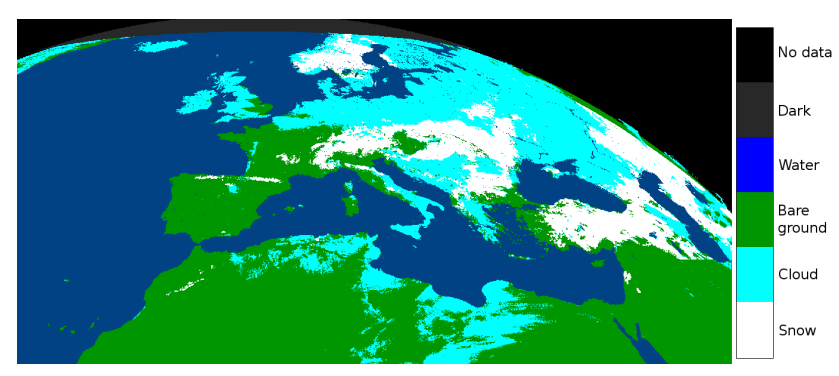

Fig. 1. Example of a MSG-SEVIRI snow cover map for 21 February 2012.

use is mainly agricultural in the lowlands and forest in the medium elevation ranges. Alpine vegetation and rocks prevail in the highest catchments.

Snow cover data used for MSG-SEVIRI evaluation include ground snow depth measurements at 178 meteorological stations (Fig. 2) and daily MODIS satellite snow cover images from April 2008 to June 2012. The snow depth readings are taken from permanent staff gauges and represent point measurements performed daily at 07:00 UTC +1 with $1 \mathrm{~cm}$ reading precision (Parajka and Blöschl, 2006). Table 2 summarizes the number of stations in different elevation zones and indicates that most of the stations are located in elevation zones between 500 and $1000 \mathrm{~m}$. In the mountains, the stations tend to be located at lower elevations, typically in the valleys, which suggest a slight bias of the validation statistics towards lower elevations.

The satellite snow cover images have been acquired by the MODIS instrument mounted on Terra and Aqua satellites of the NASA Earth Observation System. The daily Terra (MOD10A1, V005) and Aqua (MYD10A1, V005) snow products are available through the Distributed Active Archive Center located at the National Snow and Ice Data Center (NSIDC, http://www.nsidc.org). The spatial resolution of the products is $500 \mathrm{~m}$. Normalized difference snow index (NDSI) is a well-known snow index used in snow product generation from MODIS data. The NDSI takes advantage of the fact that snow reflectance is high in the visible $(0.545-0.565 \mu \mathrm{m})$ wavelengths and low in the shortwave infrared (1.628-1.652 $\mu \mathrm{m}$ ) wavelengths (Hall et al., 2006; Hall and Riggs, 2007). For the validation, the snow cover product obtained from the Terra satellite and a combined product of the Terra and Aqua satellites are used. The two products are combined to reduce cloud coverage in the mountains (Parajka and Blöschl, 2008). In the combined product, the 


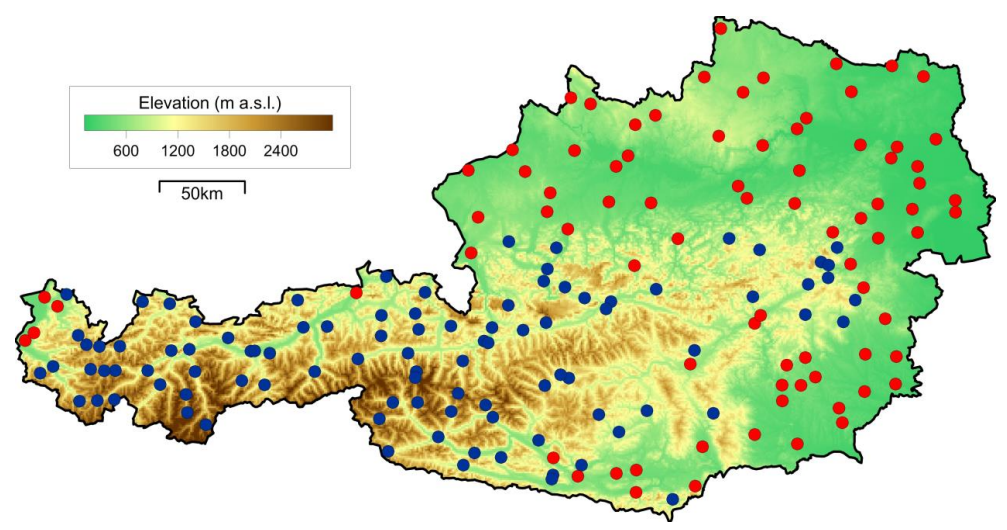

Fig. 2. Topography of Austria and location of 178 stations with daily snow depth measurements for the period April 2008-June 2012. Red and blue colors respectively represent meteorological stations located in the flatland (81 stations) and mountain (97 stations) regions according to the MSG-SEVIRI mountain mask.

pixels classified as clouds in the Terra images are updated by the Aqua pixel value of the same location if the Aqua pixel is snow or land. This approach combines satellite observations on the same day, shifted by several hours.

\section{Methodology of MSG-SEVIRI evaluation over Austria}

Evaluation of the MSG-SEVIRI snow cover accuracy is performed in two steps. In the first step, the accuracy of MSGSEVIRI is evaluated at meteorological stations by using daily snow depth observations. Snow depth observations at the stations are considered as ground truth for each MSG-SEVIRI pixel that is closest to each station. The ground is considered as snow covered if the snow depth measurement exceeds $1 \mathrm{~cm}$. In the second step, MSG-SEVIRI images are compared with daily MODIS snow cover maps. In this case, the frequency of MODIS snow, no snow and cloud classes is estimated and compared within each MSG-SEVIRI pixel.

The snow cover mapping accuracy with respect to snow depth observations is quantified by three variants of the accuracy index: $k_{\mathrm{A}}, k_{\mathrm{M}}$ and $k_{\mathrm{C}}$. The overall accuracy index $k_{\mathrm{A}}$ is estimated at each meteorological station and it is used to compare the sum of all correctly classified days where snow and no snow have been observed to the number of all cloudfree days at each meteorological station (station days) in the selected period. The seasonal accuracy index $k_{\mathrm{M}}$ is defined in a similar way, but relates the sum of all correctly classified station days (snow-snow, no snow-no snow) at different meteorological stations to the number of all cloud-free station days at those stations in a particular month. The $k_{\mathrm{M}}$ index is estimated separately for all stations located in the mountain and flatland areas as defined by the MSG-SEVIRI mountain mask (Fig. 2), respectively. The all-days accuracy index $k_{\mathrm{C}}$ relates the correctly classified station days to the total number of station days in the selected period, including days with cloud cover. It is also estimated for each month and two groups of stations (mountain and flatland).

Additional to the three accuracy indices, two types of mapping errors are quantified with respect to the ground snow depth observations: the MSG-SEVIRI misclassification of land as snow (termed here the MSG-SEVIRI overestimation error $\left.\left(k_{\mathrm{O}}\right)\right)$ and the misclassification of snow as land (termed the MSG-SEVIRI underestimation error $\left(k_{U}\right)$ ). Both types of errors relate the sum of misclassified station days to the total number of station days in each particular month and mask region.

The agreement between MSG-SEVIRI and MODIS snow cover products is quantified by the index of overall $m_{\mathrm{A}}$ and seasonal agreement $m_{\mathrm{M}}$. These indices are defined in a similar way as the $k_{\mathrm{A}}$ and $k_{\mathrm{M}}$, but instead of using snow depth observations at meteorological stations, the aggregated frequencies of MODIS snow, land and cloud classes within each MSG-SEVIRI pixel are used. The comparison is performed at the coarser spatial resolution of the MSG-SEVIRI and for those MSG-SEVIRI pixel-days where the fraction of MODIS pixels classified as clouds is less than $60 \%$. Our test simulations (not shown here) indicate that the results are insensitive to the selection of this threshold between 40 and $70 \%$. In the $m_{\mathrm{A}}$ and $m_{\mathrm{M}}$ evaluation, the ground is considered as snow covered if the fraction of MODIS snow pixels within the MSG-SEVIRI pixel is at least $50 \%$ of the sum of MODIS pixels classified as snow and land. The presence of no snow (land class) is considered in the same way; that is, the fraction of MODIS pixels classified as land is larger than the sum of snow and land pixels. The presence of no snow (land class) is considered in the same way, i.e., the frequency of MODIS pixels classified as land is larger than the sum of snow and land pixels. 


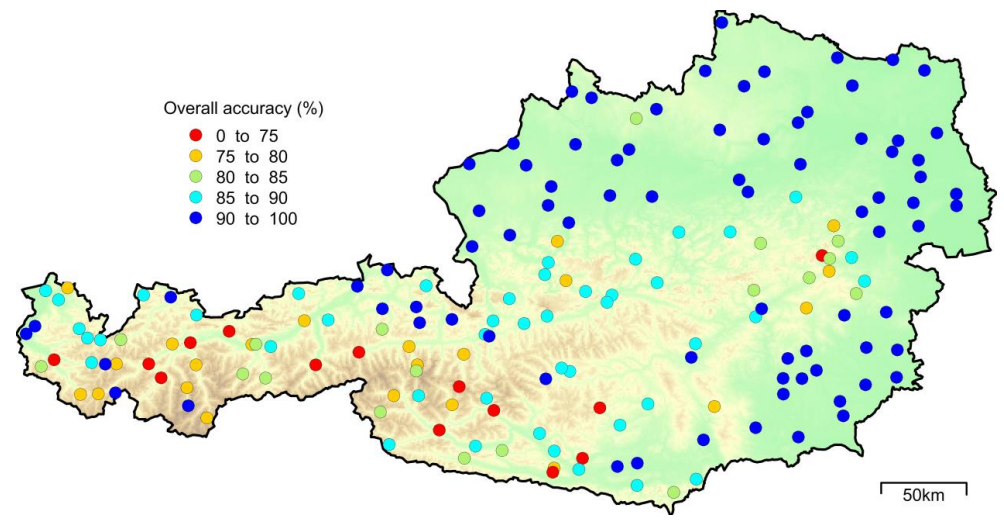

Fig. 3. MSG-SEVIRI snow product overall accuracy $k_{\mathrm{A}}(\%)$ at 178 meteorological stations for the period April $2008-\mathrm{June} 2012$.
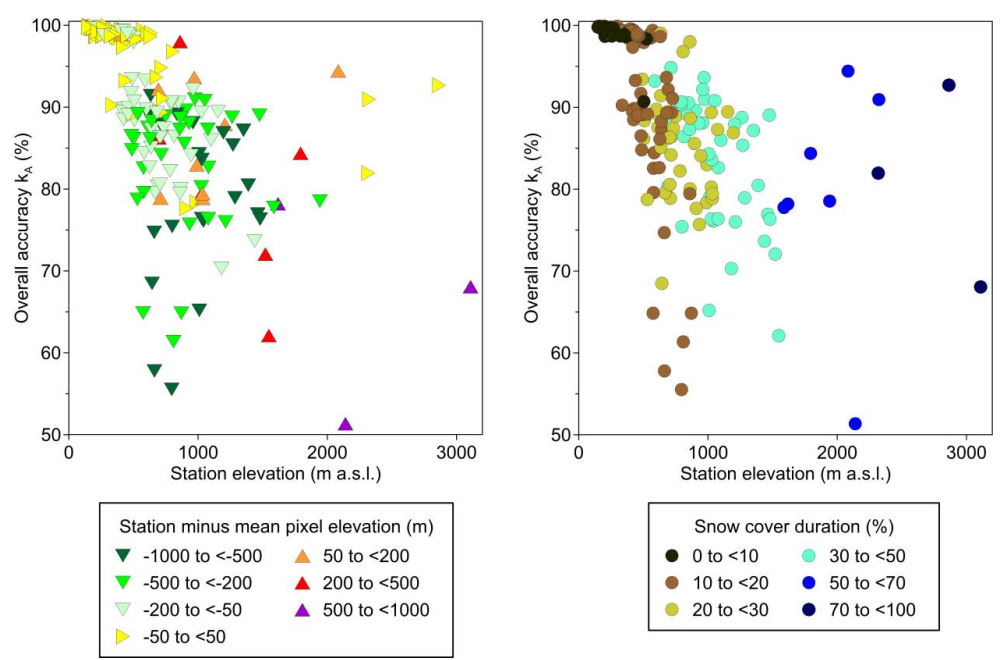

Fig. 4. Relationship between MSG-SEVIRI snow mapping accuracy $\left(k_{\mathrm{A}}\right)$ and elevation of the meteorological stations. Color of the triangles in the left panel indicates the difference between elevation of the meteorological stations and mean elevation of the respective MSG-SEVIRI pixels (as derived from a $25 \mathrm{~m}$ digital elevation model). Color of the symbols in the right panel shows relative snow cover duration observed at the meteorological stations for the period April 2008-June 2012.

\section{Results}

\subsection{Validation of MSG-SEVIRI against ground snow depth measurements}

The snow cover accuracy $\left(k_{\mathrm{A}}\right)$ of MSG-SEVIRI estimated for cloud-free days at the meteorological stations is presented in Fig. 3 and summarized in Table 3. The $k_{\mathrm{A}}$ varies between $51.3 \%$ at the Villacher Alpe (2140 $\mathrm{m}$ a.s.l.) in the Eastern Alps (Carinthia) and almost $100 \%$ in Gross-Enzersdorf (154 m a.s.1.) near Vienna. Table 3 indicates that the MSGSEVIRI accuracy is larger in the flatland than in the mountain regions, i.e., the median of $k_{\mathrm{A}}$ is 98.8 and $84.3 \%$ in the flatland and mountain regions, respectively. Figure 4 shows a clear decrease of snow mapping accuracy with increasing elevation of the meteorological stations. The results indicate that this tendency is caused mainly by increasing sub-grid
Table 3. Overall accuracy $k_{\mathrm{A}}(\%)$ of the MSG-SEVIRI snow cover product for cloud-free days at the meteorological stations. Stations in flatland and mountains are stratified according to the mountain mask used for the MSG-SEVIRI product (Fig. 2).

\begin{tabular}{lccc}
\hline Statistics & $\begin{array}{c}\text { All } \\
\text { stations }\end{array}$ & $\begin{array}{c}\text { Stations in } \\
\text { mountains }\end{array}$ & $\begin{array}{c}\text { Stations in } \\
\text { flatland }\end{array}$ \\
\hline Count & 178 & 97 & 81 \\
Minimum $k_{\mathrm{A}}$ & 51.3 & 51.3 & 78.9 \\
$25 \%$ percentile $k_{\mathrm{A}}$ & 82.6 & 78.2 & 93.9 \\
$50 \%$ percentile $k_{\mathrm{A}}$ & 89.3 & 84.3 & 98.8 \\
$75 \%$ percentile $k_{\mathrm{A}}$ & 98.7 & 88.4 & 99.4 \\
Maximum $k_{\mathrm{A}}$ & 99.9 & 94.4 & 99.9 \\
\hline
\end{tabular}




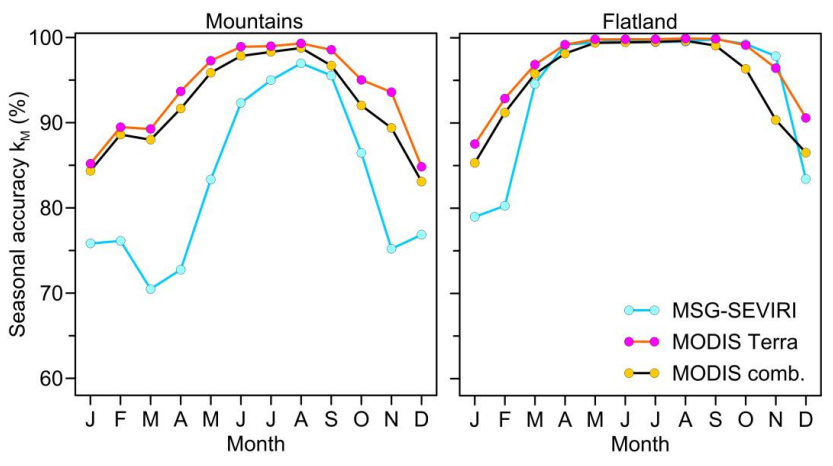

Fig. 5. Seasonal frequency of snow mapping accuracy $k_{M}$ for the MSG-SEVIRI, MODIS-Terra and MODIS-combined products estimated for cloud-free days for the period April 2008-June 2012. Left and right panels show the results for meteorological stations in the mountain (97 stations) and flatland (81 stations) regions, respectively.

topographical variability in the mountains. Meteorological stations are often situated at different elevations than the mean elevation of MSG-SEVIRI pixels, which causes biases between station and satellite snow cover observations. As is indicated in the left panel of Fig. 4, the mapping accuracy is larger for stations with smaller elevation difference. For example, the median of $k_{\mathrm{A}}$ for stations with absolute elevation difference less than $50 \mathrm{~m}$ and more than $500 \mathrm{~m}$ is 98.9 and $78.2 \%$, respectively. For the station with the largest mapping errors (Villacher Alpe), the elevation difference is larger than $960 \mathrm{~m}$. The stations located significantly below or above the pixel mean may have noticeably different snow cover observations (right panel of Fig. 4). The snow cover observations at meteorological stations in Austria show a clear linear relationship $\left(R^{2}=88 \%\right)$ between snow cover duration and the altitude, indicating an increase of snow cover duration by $2.8 \% / 100 \mathrm{~m}$ (not shown here). An elevation difference of $500 \mathrm{~m}$ can therefore be easily transferred in about $14 \%$ difference in snow cover duration and thus different snow cover mapping accuracy. Interestingly, the MSG-SEVIRI mapping accuracy is larger than $90 \%$ for two stations situated above $2000 \mathrm{~m}$ a.s.l. (Ischgl-Idalpe and Pitztaler Gletscher), but located approximately at the mean elevation of the MSGSEVIRI pixel. This finding indicates the importance of the spatial resolution and sub-grid topographical variability for the assimilation of satellite snow cover images in operational hydrological applications.

The seasonal frequencies of MSG-SEVIRI snow mapping accuracy $\left(k_{\mathrm{M}}\right)$ are presented in Fig. 5. The results show that, in the mountains, the $k_{\mathrm{M}}$ accuracy varies between 70 and $77 \%$ in the winter and between 92 and $97 \%$ in the summer months. The flatland region typically has much shorter snow coverage, which most likely results in larger $k_{\mathrm{M}}$ accuracy between April and October, but larger mapping errors $\left(k_{\mathrm{M}}\right.$ between 79 and $83 \%$ ) in the winter months. As compared to $k_{\mathrm{M}}$
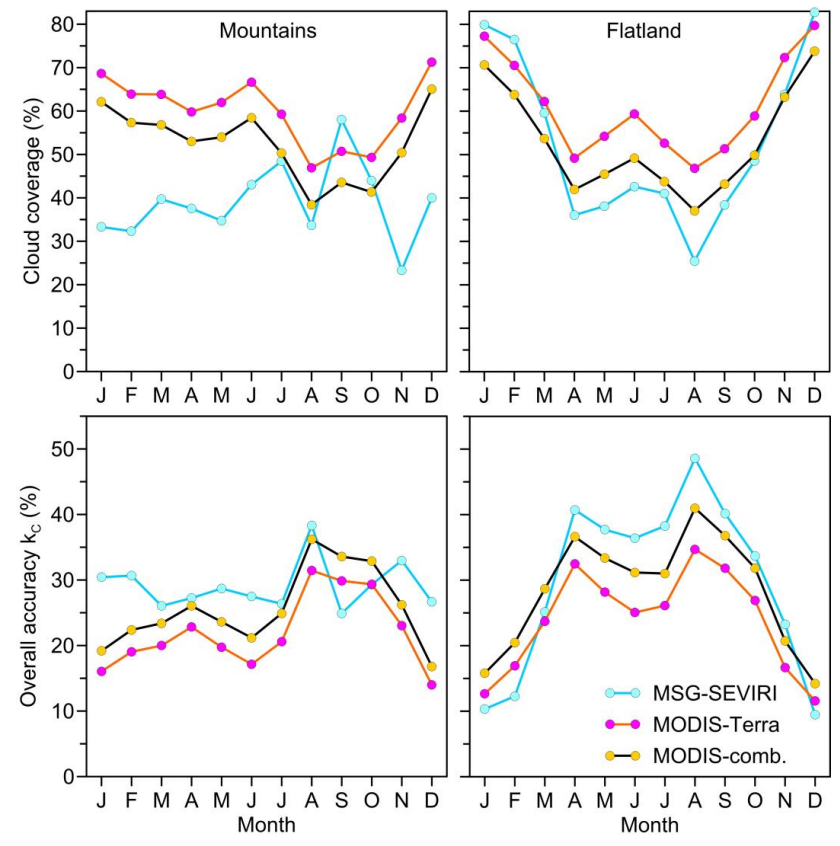

Fig. 6. Seasonal frequency of the clouds (top panels) and snow mapping accuracy $k_{\mathrm{C}}$ for the MSG-SEVIRI, MODIS-Terra and MODIS-combined products estimated for all days for the period April 2008-June 2012. Left and right panels show the results for meteorological stations in the mountain (97 stations) and flatland (81 stations) regions, respectively.

obtained for the MODIS/Terra and MODIS/combined snow cover products, the MSG-SEVIRI mapping accuracy is 10$13 \%$ lower in the mountains and $3-11 \%$ lower in the flatland area in the winter months. However, the MSG-SEVIRI product contains significantly less pixels classified as clouds than MODIS, particularly in the mountains (Fig. 6, top panels). Here, the merging of 32 MSG-SEVIRI images per day reduces cloud coverage between 15 and $29 \%$ for the period November-June as compared to the MODIS-combined product. The cloud reduction is even about $7 \%$ larger when compared to the MODIS-Terra product. For the period JulyOctober, the cloud coverage of MSG-SEVIRI is similar to that of MODIS in the mountains. Interestingly, in the flatland areas a decrease in cloud coverage is observed only for the period April and September. In the winter months, MSGSEVIRI indicates cloud coverage larger than $75 \%$, which is similar to or even slightly larger than indicated by the MODIS products. This is probably caused by the use of different cloud masking algorithms.

The reduction in clouds, particularly in the mountains, then translates into an improvement of all-days mapping accuracy $k_{\mathrm{C}}$ (Fig. 6, bottom panels). The $k_{\mathrm{C}}$ accuracy assumes clouds as a mapping error, and it varies for MSG-SEVIRI between 26 and $31 \%$ (mountains) and between 9 and $25 \%$ (flatland areas) in the winter and spring periods. In the mountains, this is about $3-14 \%$ larger than the $k_{\mathrm{C}}$ obtained for the 
Table 4. Seasonal frequency of overestimation $\left(k_{\mathrm{O}}\right)$ and underestimation $\left(k_{\mathrm{U}}\right)$ mapping errors $(\%)$ estimated for the MSG-SEVIRI, MODISTerra and MODIS-combined snow cover products for the period April 2008-June 2012. The mapping errors are estimated at 97 and 81 meteorological stations in the mountain (Mnt) and flatland (Flat) areas, respectively.

\begin{tabular}{lcccccc}
\hline Season & $\begin{array}{c}\text { MSG- } \\
\text { SEVIRI } \\
\text { overest. } k_{\mathrm{O}} \\
(\text { Mnt/Flat })\end{array}$ & $\begin{array}{c}\text { MSG- } \\
\text { SEVIRI } \\
\text { underst. } k_{\mathrm{U}} \\
(\text { Mnt/Flat) }\end{array}$ & $\begin{array}{c}\text { MODIS- } \\
\text { Terra } \\
\text { overest. } k_{\mathrm{O}} \\
(\text { Mnt/Flat })\end{array}$ & $\begin{array}{c}\text { MODIS- } \\
\text { Terra } \\
\text { underest. } k_{\mathrm{U}} \\
(\text { Mnt/Flat) }\end{array}$ & $\begin{array}{c}\text { MODIS- } \\
\text { comb. } \\
\text { overest. } k_{\mathrm{O}} \\
(\text { Mnt/Flat) }\end{array}$ & $\begin{array}{c}\text { MODIS- } \\
\text { comb. } \\
\text { underest. } k_{\mathrm{U}} \\
\text { (Mnt/Flat) }\end{array}$ \\
\hline January & $4.6 / 0.4$ & $6.3 / 2.4$ & $1.0 / \mathbf{1 . 0}$ & $\mathbf{1 . 8} / \mathbf{0 . 8}$ & $1.4 / 1.6$ & $\mathbf{2 . 2 / 1 . 2}$ \\
February & $4.3 / 0.4$ & $\mathbf{6 . 8} / \mathbf{2 . 6}$ & $0.7 / 0.7$ & $1.5 / 0.6$ & $1.1 / 1.2$ & $1.8 / 0.8$ \\
March & $6.1 / 0.3$ & $5.7 / 1.1$ & $1.1 / 0.3$ & $1.3 / 0.4$ & $1.5 / 0.7$ & $1.7 / 0.6$ \\
April & $\mathbf{8 . 8} / 0.1$ & $2.5 / 0.2$ & $0.8 / 0.1$ & $0.7 / 0.2$ & $1.4 / 0.5$ & $1.0 / 0.2$ \\
May & $5.5 / 0.2$ & $1.1 / 0.0$ & $0.3 / 0.1$ & $0.3 / 0.0$ & $0.7 / 0.2$ & $0.3 / 0.0$ \\
June & $2.2 / 0.1$ & $0.4 / 0.0$ & $0.1 / 0.0$ & $0.1 / 0.0$ & $0.3 / 0.2$ & $0.1 / 0.0$ \\
July & $1.3 / 0.2$ & $0.2 / 0.0$ & $0.1 / 0.0$ & $0.1 / 0.0$ & $0.3 / 0.2$ & $0.1 / 0.0$ \\
August & $0.9 / 0.2$ & $0.4 / 0.0$ & $0.1 / 0.0$ & $0.1 / 0.0$ & $0.3 / 0.1$ & $0.2 / 0.0$ \\
September & $1.0 / 0.1$ & $0.3 / 0.0$ & $0.3 / 0.0$ & $0.1 / 0.0$ & $1.0 / 0.3$ & $0.1 / 0.0$ \\
October & $4.0 / 0.2$ & $1.1 / 0.0$ & $\mathbf{1 . 2} / 0.2$ & $0.3 / 0.0$ & $2.4 / 1.2$ & $0.4 / 0.0$ \\
November & $6.1 / 0.2$ & $7.9 / 0.4$ & $1.1 / 0.4$ & $0.5 / 0.2$ & $\mathbf{2 . 4} / \mathbf{2 . 0}$ & $0.7 / 0.3$ \\
December & $5.1 / 0.5$ & $4.6 / 1.5$ & $0.9 / 0.7$ & $1.6 / 0.5$ & $1.4 / 1.6$ & $2.0 / 0.6$ \\
\hline
\end{tabular}

The largest mapping error for each product and mask area is marked by bold print.

MODIS data set. In the flatland areas, the large cloud coverage in winter does not enable an increase in $k_{\mathrm{C}}$ as compared to MODIS products. The evaluation of $k_{\mathrm{C}}$ clearly indicates the tradeoff between increased cloud reduction due to higher temporal sampling (32 images per day) and higher mapping error due to coarser spatial resolution (particularly in the mountains) of the MSG-SEVIRI snow product.

The seasonal frequency of MSG-SEVIRI mapping errors is summarized in Table 4 . Table 4 compares the overestimation $\left(k_{\mathrm{O}}\right)$ and underestimation $\left(k_{\mathrm{U}}\right)$ errors of MSG-SEVIRI, MODIS-Terra and MODIS-combined data sets as observed at meteorological stations. The general distribution of MSGSEVIRI errors shows a typical seasonal pattern of larger errors in winter and spring and smaller errors in summer. In comparison to MODIS products, the MSG-SEVIRI mapping errors are significantly larger during the snowmelt season in the mountains (4-9\%) and somewhat larger during the winter months in the flatlands (1-3\%). A detailed analysis of $k_{\mathrm{O}}$ and $k_{\mathrm{U}}$ errors (Fig. 7) indicates that the MSG-SEVIRI mapping errors are much larger at stations that are located at different elevations than the mean elevation of the closest MSG-SEVIRI pixel. The largest $k_{\mathrm{O}}$, i.e., more than $25 \%$ in April or $15 \%$ in November, is estimated at stations that are located more than $500 \mathrm{~m}$ lower than the pixel mean. Similarly, the largest $k_{\mathrm{U}}$ errors are found at stations located more than $500 \mathrm{~m}$ above the pixel mean. The evaluation of MSGSEVIRI mapping errors at stations that are located at approximately the same elevation (yellow triangles in Fig. 7) indicates that the MSG-SEVIRI tends to more frequently underestimate snow cover in winter than overestimating it. The largest $k_{\mathrm{O}}$ errors are less than $0.5 \%$, but $k_{\mathrm{U}}$ errors exceed $3 \%$ in the winter months.
Table 5. Overall agreement $m_{\mathrm{A}}(\%)$ between MSG-SEVIRI and MODIS-combined snow cover products for MSG-SEVIRI pixels with less than $60 \%$ MODIS cloud coverage. The agreement $m_{\mathrm{A}}$ accuracy is evaluated for all MSG-SEVIRI pixels, flatland and mountain mask areas in Austria.

\begin{tabular}{lccc}
\hline Statistics & $\begin{array}{c}\text { All } \\
\text { pixels }\end{array}$ & $\begin{array}{c}\text { Pixels in } \\
\text { mountains }\end{array}$ & $\begin{array}{c}\text { Pixels in } \\
\text { flatland }\end{array}$ \\
\hline Count & 2635 & 1403 & 1232 \\
Minimum $m_{\mathrm{A}}$ & 57.3 & 57.3 & 64.4 \\
$25 \%$ percentile $m_{\mathrm{A}}$ & 78.4 & 77.4 & 81.1 \\
$50 \%$ percentile $m_{\mathrm{A}}$ & 82.5 & 81.6 & 82.9 \\
$75 \%$ percentile $m_{\mathrm{A}}$ & 84.3 & 85.2 & 84.1 \\
Maximum $m_{\mathrm{A}}$ & 92.7 & 92.7 & 86.0 \\
\hline
\end{tabular}

\subsection{Comparison between MSG-SEVIRI and MODIS snow cover data}

The overall agreement between the MSG-SEVIRI and MODIS-combined maps $\left(m_{\mathrm{A}}\right)$ is summarized in Table 5. The $m_{\mathrm{A}}$ vary between 57.3 and $92.7 \%$, with a median of $82.5 \%$. The difference in medians between the flatland $(82.9 \%)$ and mountain $(81.6 \%)$ regions is not large. The spatial patterns indicate (Fig. 8) that $m_{\mathrm{A}}$ is between 80 and $90 \%$ in the flatland, with an exception in the hilly region at the border between Upper and Lower Austria (Waldviertel), where $m_{\mathrm{A}}$ is less than $75 \%$. In the mountains, the $m_{\mathrm{A}}$ variability tends to be larger. The $m_{\mathrm{A}}$ agreement is over $90 \%$ in the high mountain locations, but smaller than $65 \%$ in the Alpine valleys in western Austria. It is also less than $70 \%$ in the southeastern part of the mountain mask region (Styria) (Lahtinen et al., 2009). The relationship between $m_{\mathrm{A}}$ and altitude is plotted 


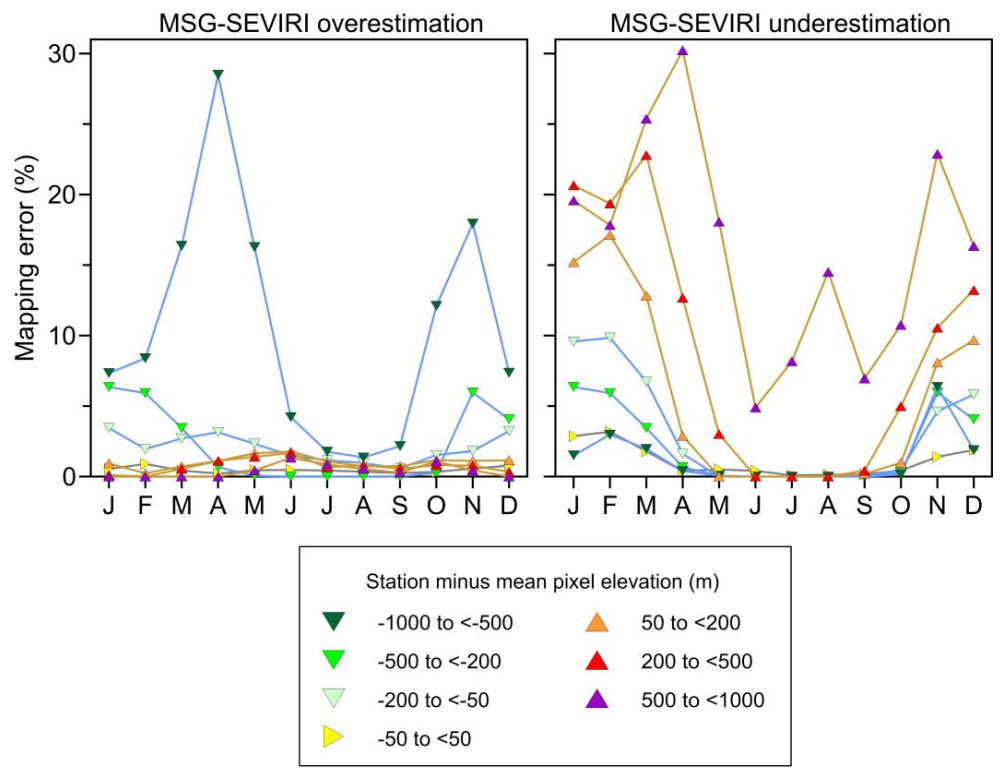

Fig. 7. Seasonal frequency of MSG-SEVIRI overestimation ( $k_{\mathrm{O}}$, left panel) and underestimation $\left(k_{\mathrm{U}}\right.$, right panel) errors summarized for stations with different elevation difference between meteorological station and respective MSG-SEVIRI pixel mean. The elevation difference is estimated as station elevation minus mean pixel elevation (as derived from a $25 \mathrm{~m}$ digital elevation model).

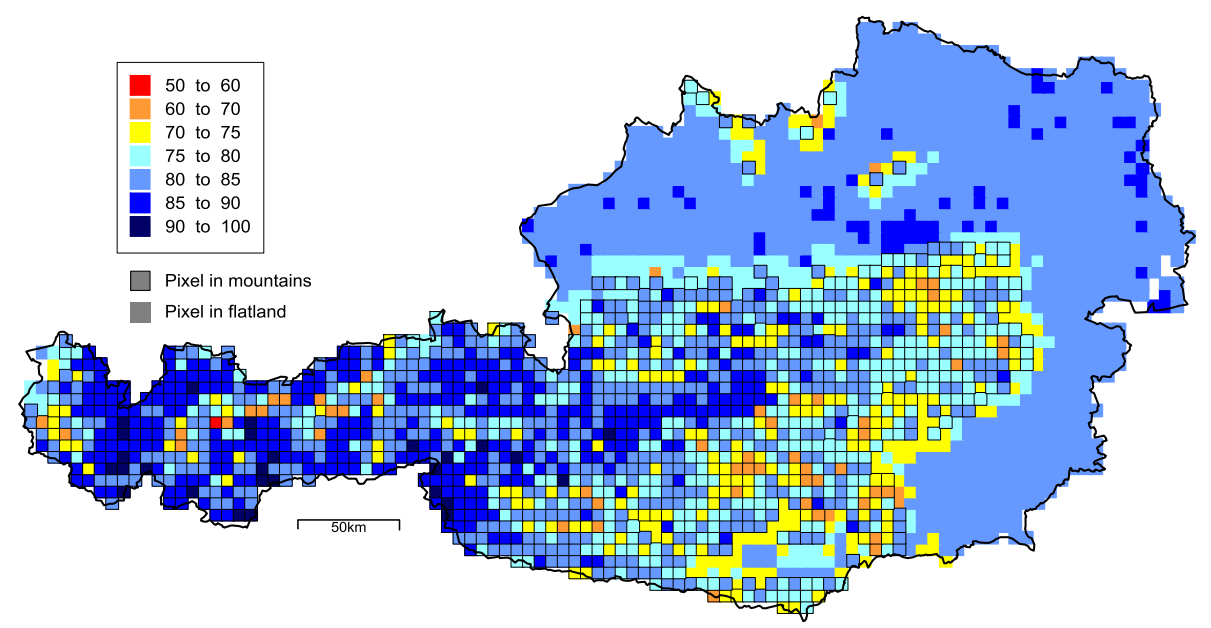

Fig. 8. Overall accuracy $k_{\mathrm{A}}$ of MSG-SEVIRI with respect to the MODIS-combined product for the period April 2008-June 2012. $k_{\mathrm{A}}$ is estimated for the MSG-SEVIRI pixels where MODIS cloud coverage is less than $60 \%$. Pixels with black outline indicate the MSG-SEVIRI mountain mask.

in Fig. 9. While in the flatlands $m_{\mathrm{A}}$ tends to decrease with elevation; in the mountains there is a tendency of increasing $m_{\mathrm{A}}$ with altitude. The results show that the largest $m_{\mathrm{A}}$ variability in Austria is in the regions with altitudes between 700 and $1500 \mathrm{~m}$.

The seasonal variability $\left(m_{\mathrm{M}}\right)$ in the agreement between MSG-SEVIRI and MODIS is presented in Fig. 10. In the flatland areas (red line), $m_{\mathrm{M}}$ is the largest in April and July and less than $70 \%$ in the winter months. The $m_{\mathrm{M}}$ amplitude is smaller in the mountains (blue line), ranging from more than $85 \%$ in May, June and August to $70 \%$ in September.
A more detailed evaluation of the spatio-temporal patterns of the agreement between MSG-SEVIRI and MODIS is presented in Figs. 11 and 12. Figure 11 compares the spatial patterns of the frequencies of three MSG-SEVIRI and MODIS mapping classes - clouds, snow, and no snow. It is clear that the agreement between the snow cover products is the largest for mapping the clouds, for mapping the land in the flatland and snow in the high alpine areas. These cases occur in more than $25 \%$ of days in the selected period, in most of the MSG-SEVIRI pixels. The MSG-SEVIRI maps snow, while the MODIS-combined product indicates clouds in $10-15 \%$ 


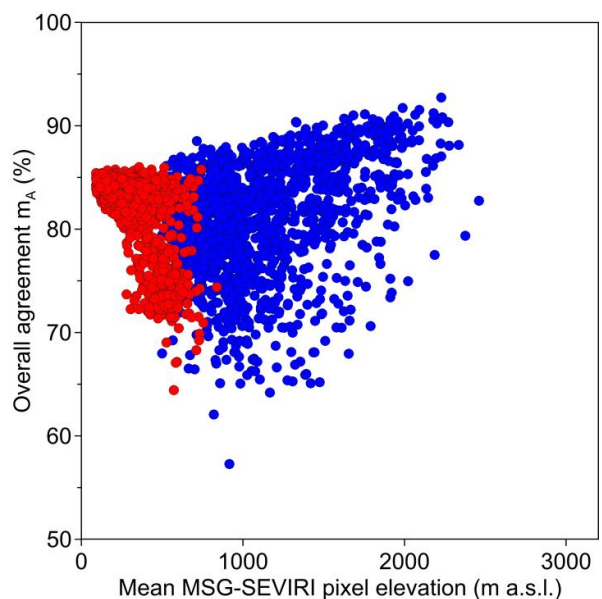

Fig. 9. Relationship between mean MSG-SEVIRI pixel elevation and the overall agreement $\left(m_{\mathrm{A}}\right)$ between the MSG-SEVIRI and MODIS-combined products. Red and blue points represent MSG-SEVIRI pixels in the flatland and mountain mask areas, respectively.

of days in the Alps. Interestingly, in the flatland, there are only a few days when both MSG-SEVIRI and MODIS indicate snow. The spatial patterns of the disagreement between the products (i.e., MSG-SEVIRI maps no presence of snow (land), but MODIS indicates snow) show that most of the cases are in Upper Austria, Styria and the mountain valleys. An opposite case occurs quite frequently in the mountain valleys of western Austria, where MSG-SEVIRI and MODIS map snow and land in $10-15 \%$ of days, respectively. Figure 12 shows that MSG-SEVIRI overestimates snow in comparison to MODIS (middle panels) mainly in the summer for both mountain and flatland areas. The bottom panel (Fig. 12) indicates that the opposite case (i.e., MSG-SEVIRI underestimates snow in the winter) is less frequent (up to $10 \%$ ). There is quite a large frequency of days where MSG-SEVIRI maps land and MODIS indicates clouds. These cases occur in more than $20 \%$ of the days of each month in the flatland area. In the mountains, the reduction of clouds is noticeable in the winter months, where MODIS indicates clouds, but MSG-SEVIRI maps snow in more than $15 \%$ of the days.

\section{Discussion and conclusions}

This study evaluates the snow cover mapping accuracy of the MSG-SEVIRI operational product. This product is based on blending 32 consecutive images per day, which is foreseen as an alternative to different filtering methods used for cloud reduction in optical remote sensing products. The limitation of the product is a coarser spatial resolution of about $5 \mathrm{~km}$. Our results indicate that the blending of multiple observations during the day allows a significant cloud reduction in Austria. The mean annual cloud coverage of the MSG-SEVIRI

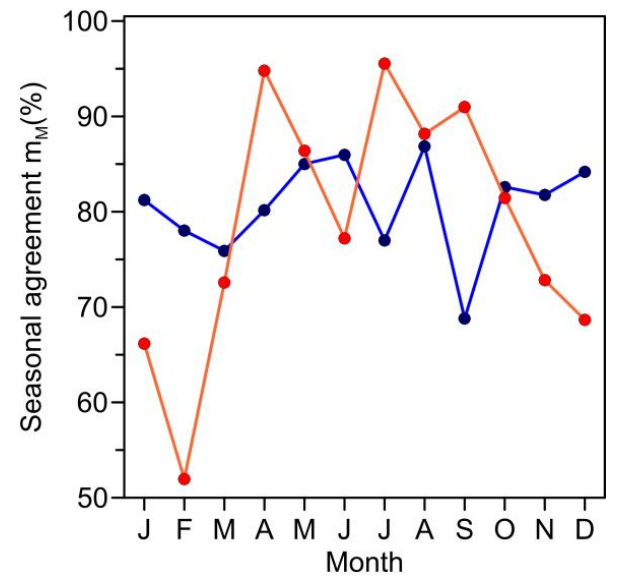

Fig. 10. Seasonal agreement $m_{\mathrm{M}}$ between the MSG-SEVIRI and MODIS-combined products for MODIS cloud-free pixels for the period April 2008-June 2012. Red and blue lines represent mountain and flatland areas, respectively.

product is less than $30 \%$, which is 23 and $30 \%$ lower than obtained by the MODIS-combined and MODIS-Terra snow cover products, respectively. Such cloud reduction is similar to that obtained by 1-day temporal filter performed on the MODIS-combined product (Parajka and Blöschl, 2008). The results are consistent with the preliminary MSG-SEVIRI assessment study (Surer and Akyurek, 2012), which indicates a 31-49\% cloud reduction in mountainous parts of Turkey in the winter season. Despite the coarser spatial resolution of MSG-SEVIRI, the overall mapping accuracy is large. The average accuracy for cloud-free days is $89 \%$, which is $5 \%$ lower than obtained by the MODIS-combined product, but similar to that obtained by land-surface (JULES) model simulations driven by a regional climate model HadRM3-P (Parajka et al., 2010). The overall accuracy also relates well with the hit rate measure of Surer and Akyurek (2012), which is in between 68 and $81 \%$ in winter. The accuracy with respect to all weather conditions (in all weather conditions assessments the pixels with clouds are considered as mapping errors) is, however, about 3-4\% larger than obtained by the MODIS product. The larger frequency of snow cover information, even for coarse resolution, indicates the potential of MSG-SEVIRI for operational assimilation into hydrologic models.

The analysis of mapping errors indicates that MSGSEVIRI tends to underestimate snow cover, particularly in flatland areas. Large errors are also found in the Alpine region characterized by large topographical and snow cover variability. The errors are noticeably larger at stations that are located at different elevations than the mean of the MSGSEVIRI pixels. The differences in mapping accuracy clearly indicate the limits of using meteorological stations for validating coarse satellite products. In order to account for scaling relationships between point measurement and pixel size 


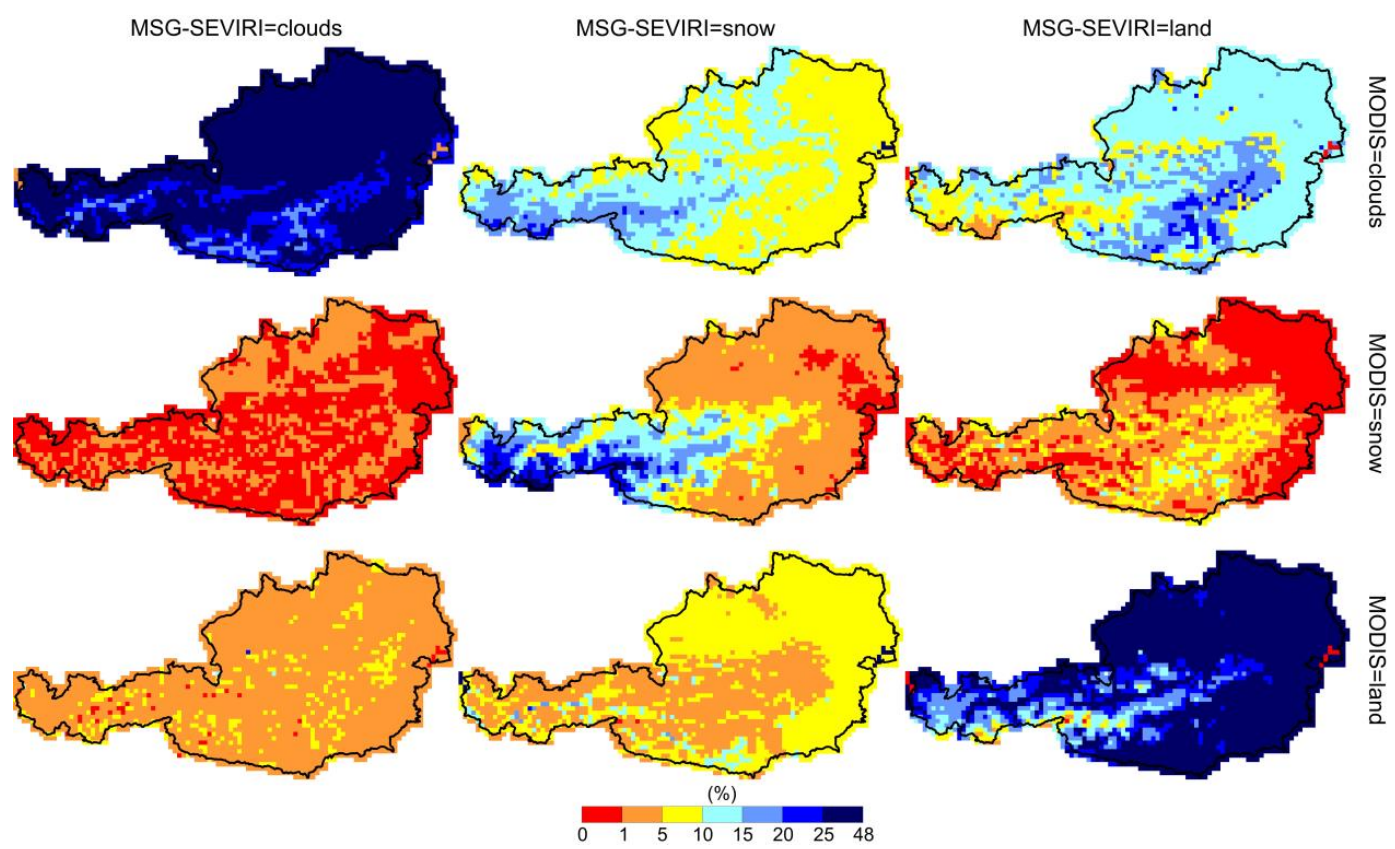

Fig. 11. Relative frequency of days with agreement and disagreement between the MSG-SEVIRI and MODIS-combined snow cover products for the period April 2008-June 2012.

(Blöschl and Kirnbauer, 1992; Blöschl, 1999; Skøien et al., 2003) some studies used different thresholds for considering ground as snow covered. For example, Simic et al. (2004) examined the sensitivity of the mapping accuracy to the reference threshold of 1 and $3 \mathrm{~cm}$ and found that the difference is small, ranging approximately between -2 and $4 \%$. In this study, a $1 \mathrm{~cm}$ threshold is used in order to be consistent and comparable with other studies performed in Austria. In the future, the sensitivity of results to this reference threshold should be investigated in more detail.

The comparison between MSG-SEVIRI and MODIS snow cover products shows a good overall agreement. The use of the MSG-SEVIRI snow product in hydrological modeling is under study, but calibration of a conceptual hydrological model by using MSG-SEVIRI snow cover product has been performed. It is observed that the multi-objective calibration, in which MSG-SEVIRI snow cover data is used beside the runoff data, improved the snow cover estimation of the hydrological model (Akyurek et al., 2013).

The snow retrieval algorithms for MSG-SEVIRI and MODIS snow products are more or less the same. The comparison between the normalized difference snow index (NDSI), used as the retrieval algorithm for MODIS product, and SI, used as the retrieval algorithm for MSG-SEVIRI product, shows a good relationship for several clear-sky MSG-SEVIRI images (Surer and Akyurek, 2012). The selected SI threshold value of 0.6 for the snow-cover area retrieval corresponds to 0.2 for the NDSI value. For the MODIS products the NDSI value for $50 \%$ snow-covered areas is taken as 0.4 (Dozier, 1989; Hall et al., 2002). The aim of selecting SI as 0.6 is to include the partial snow-covered areas in the retrieval of MSG-SEVIRI snow product. The differences are because of coarse spatial resolution of MSGSEVIRI. The finding in this study indicates the importance of spatial resolution and sub-grid topographical variability for the use of satellite snow cover images in operational hydrological applications or climatological studies.

The comparison between MSG-SEVIRI and MODIS snow cover products shows a good overall agreement. The overestimation and underestimation errors of MSG-SEVIRI snow product is larger compared to the MODIS-Terra snow product. In both of the products underestimation error is observed in the winter months and overestimation error is observed in the spring and summer months. The overestimation and underestimation are more pronounced for mountainous areas compared to flat lands for MSG-SEVIRI snow product. Besides the spatial resolution affecting the snow mapping accuracy, the difference in the viewing geometries of two sensors may have an effect on the snow mapping. The view geometry may be one of the major error sources in snow mapping algorithms. The influence of the varying MODIS view zenith angles on snow mapping algorithm must be investigated in detail. As view zenith angle increases, it is known that NDSI decreases (Xin et al., 2012). Since MODIS observes the surfaces at a much smaller view zenith angle (VZA) than the SEVIRI, it detects more snow cover area. That may be the reason to observe large underestimation errors for SEVIRI compared to MODIS in winter months. The narrow band width in the Green and Mid. Infrared portion of the spectrum for MODIS creates the possibility to map more snow 

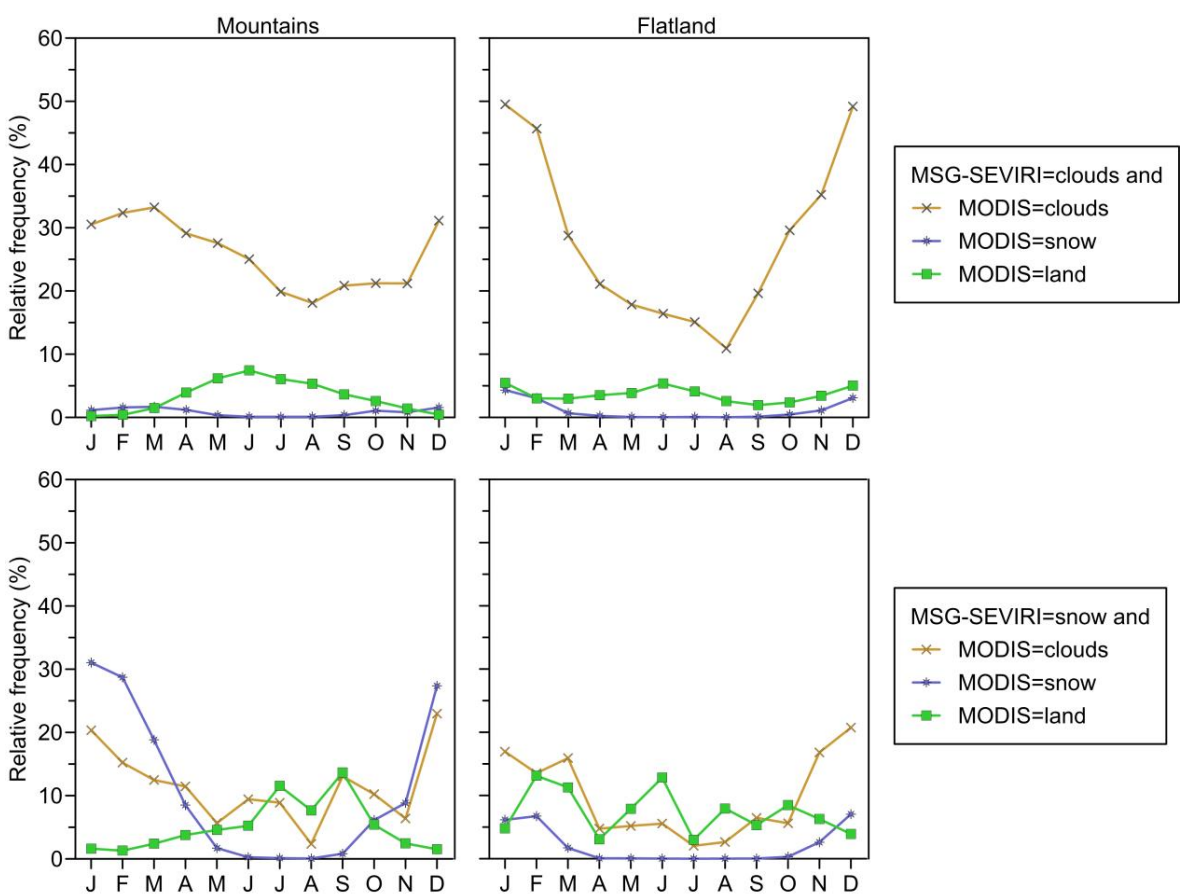

$$
\begin{aligned}
& \text { MSG-SEVIRI=snow and } \\
& * \text { MODIS=clouds } \\
& * \text { MODIS }=\text { snow } \\
& -- \text { MODIS=land }
\end{aligned}
$$
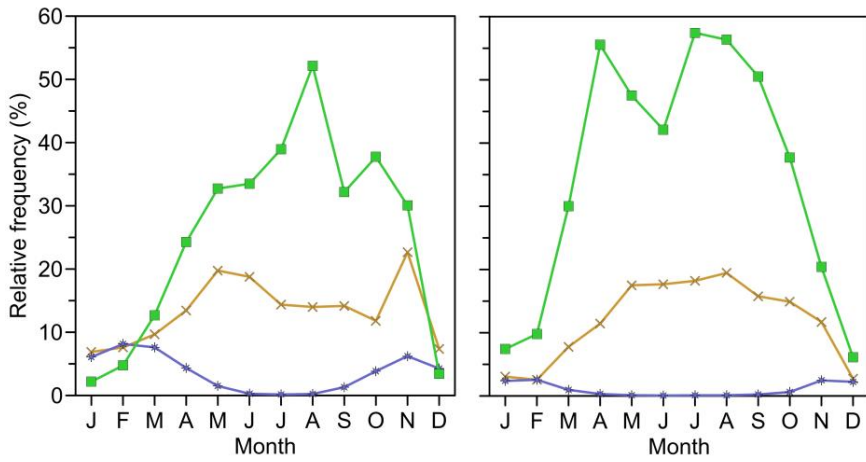

MSG-SEVIRI=land and

* MODIS=clouds

* MODIS=snow

-- MODIS=land

Fig. 12. Mean seasonal frequency of days with agreement and disagreement between the MSG-SEVIRI and MODIS-combined snow cover products in each month for the period April 2008-June 2012.

compared to SEVIRI. The overestimation for spring months is due to the high percentage of fractional snow cover due to melting in these months. The MSG-SEVIRI algorithm tends to map more snow for fractional snow-covered areas. Neither the effect of complex topography, nor the shadows were held in the MSG-SEVIRI snow mapping algorithm. Therefore the MSG-SEVIRI algorithm can be modified with the use of a proper DEM in order to correct the topography effect.

Better snow cover information can be retrieved by using MSG-SEVIRI and MODIS snow products together. The cloud-contaminated MODIS snow pixels can be reclassified according to the values observed from the MSG-SEVIRI snow product. The merging of snow products having comparatively better spatial resolution (MODIS) and temporal resolution (MSG-SEVIRI) can be studied as a future work.

Besides the importance of spatial resolution of snow products, a better temporal resolution helps to increase the cloud/snow discrimination, which is very important for the use of satellite snow products in further analysis. The new sensors and satellite missions to be used for hydrological and climatological studies can be designed according to an optimum spatial and temporal resolution.

Acknowledgements. This study was prepared within the framework of HSAF project funded by EUMETSAT. The second author was supported by EUMETSAT as a visiting scientist at METU within the H-SAF project. Thanks to Kenan Bolat for his technical support. The authors would like to thank the Central Institute for Meteorology and Geodynamics (ZAMG) for providing the snow depth data.

Edited by: A. Loew 


\section{References}

Akyurek, Z., Surer, S., and Parajka, J.: Calibration of a Conceptual Hydrological Model Using EUMETSAT Snow Covered Area Product, AGU Fall Meeting, San Francisco, USA, 2013.

Aminou, D. M. A.: MSG's SEVIRI Instrument, ESA Bull., 111, 15-17, 2002.

Blöschl, G.: Scaling issues in snow hydrology, Hydrol. Process., 13, 2149-2175, 1999.

Blöschl, G. and Kirnbauer, R.: Point snowmelt models with different degrees of complexity - internal processes, J. Hydrol., 129, 127-147, 1991.

Blöschl, G. and Kirnbauer, R.: An analysis of snow cover patterns in a small Alpine catchment, Hydrol. Process., 6, 99-109, 1992.

Blöschl, G., Gutknecht, D., and Kirnbauer, R.: Distributed snowmelt simulations in an Alpine catchment, 2. Parameter study and model predictions, Water Resour. Res., 27, 3181-3188, 1991.

Brubaker, K. L., Pinker, R. T., and Deviatova, E.: Evaluation and comparison of MODIS and IMS snow-cover estimates for the continental United States using station data, J. Hydrometeorol., 6, 1002-1017, 2005.

Dozier, J.: Spectral signature of alpine snow cover from Landsat Thematic Mapper, Remote Sens. Environ., 28, 9-22, 1989.

Gafurov, A. and Bárdossy, A.: Cloud removal methodology from MODIS snow cover product, Hydrol. Earth Syst. Sci., 13, 13611373, doi:10.5194/hess-13-1361-2009, 2009.

Hall, D. K. and Riggs, G. A.: Accuracy assessment of the MODIS snow products. Hydrol. Process., 21, 1534-1547, 2007.

Hall, D. K., Riggs, G. A., Salomonson, V. V., DiGiromamo, N., and Bayr, K. J.: MODIS Snow-Cover Products, Remote Sens. Environ., 83, 181-194, 2002.

Hall, D. K., Riggs, G. A., and Salomonson, V. V.: MODIS/Terra Snow Cover Daily L3 Global $500 \mathrm{~m}$ Grid V005, USA, Digital media, updated daily, National Snow and Ice Data Center, Boulder, Colorado, 2006.

Hall, D. K., Riggs, G. A., Foster, J. L., and Kumar, S. V.: Development and Evaluation of a Cloud-Gap-Filled Modis Daily SnowCover Product, Remote Sens. Environ., 114, 496-503, 2010.

HSAF: Algorithms Theoretical Baseline Document for product H10 - SN-OBS-1, available at: http://hsaf.meteoam.it/ATDD-sn.php (last access: 7 October 2013), 2010.

HSAF: Product Validation Report for product H10-SN-OBS1, available at: http://hsaf.meteoam.it/PVR-sn.php (last access: 7 October 2013), 2011.

Klein, A. and Barnett, A. C.: Validation of daily MODIS snow cover maps of the Upper Rio Grande River Basin for the 2000-2001 snow year, Remote Sens. Environ., 86, 162-176, 2003.

Lahtinen, P., Erturk, A. G., Pulliainen, J., and Koskinen, J.: Merging flat/forest and mountainous snow products for extended European area, in: Geoscience and Remote Sensing Symposium, 2009 IEEE International, IGARSS 2009, Cape Town, 2009.
Nester, T., Kirnbauer, R., Parajka, J., and Blöschl, G.: Evaluating the snow component of a flood forecasting model, Hydrol. Res., 43, 762-779, 2012.

NWCSAF - Nowcasting Satellite Application Facility: Usermanual for the Cloud Products of the Nowcasting Satellite Application Facilities, http://www.nwcsaf.org/HD/MainNS.jsp (last access: 7 October 2013), 2007.

Parajka, J. and Blöschl, G.: Validation of MODIS snow cover images over Austria, Hydrol. Earth Syst. Sci., 10, 679-689, doi:10.5194/hess-10-679-2006, 2006.

Parajka, J. and Blöschl, G.: Spatio-temporal combination of MODIS images - potential for snow cover mapping, Water Resour. Res., 44, W03406, doi:10.1029/2007WR006204, 2008.

Parajka, J. and Blöschl, G.: MODIS-based Snow Cover Products, Validation, and Hydrologic Applications, in: Multiscale Hydrologic Remote Sensing Perspectives and Applications, edited by: Chang, Y. and Ni-Bin, H., CRC Press, 185-212, 2012.

Parajka, J., Dadson, S., Lafon, T., and Essery, R.: Evaluation of snow cover and depth simulated by a land surface model using detailed regional snow observations from Austria, J. Geophys. Res., 115, D24117, doi:10.1029/2010JD014086, 2010.

Romanov, P., Gutman, G., and Csiszar, I.: Automated monitoring of snow cover over North America with multispectral satellite data, J. Appl. Meteorol., 39, 1866-1880, 2000.

Romanov, P., Tarpley, D., Gutman, G., and Carroll, T.: Mapping and monitoring of the snow cover fraction over North America, J. Geophys. Res., 108, 8619, doi:10.1029/2002JD003142, 2003.

Siljamo, N. and Hyvärinen, O.: New geostationary satellite-based snow-cover algorithm, J. Appl. Meteorol. Clim., 50.6, 12751290, doi:10.1175/2010JAMC2568.1, 2011.

Simic, A., Fernandes, R., Brown, R., Romanov, P., and Park, W.: Validation of VEGETATION, MODIS, and GOES+SSM/I snow cover products over Canada based on surface snow depth observations, Hydrol. Process., 18, 1089-1104, 2004.

Skøien, J. O., Blöschl, G., and Western, A. W.: Characteristic space scales and timescales in hydrology, Water Resour. Res., 39, 1304 doi:10.1029/2002WR001736, 2003.

Surer, S.: Real-time snow cover mapping over mountainous areas of Europe using MSG-SEVIRI imagery, Thesis (Masters), Middle East Technical University, Turkey, http://etd.lib.metu.edu.tr/ upload/12609911/index.pdf (last access: 12 September 2013), 2008.

Surer, S. and Akyurek, Z.: Evaluating the utility of the EUMETSAT HSAF snow recognition product over mountainous areas of eastern Turkey, Hydrolog. Sci. J., 57, 1684-1694, 2012.

Xin, Q., Woodcock, C. E., Liu, J., Tan, B., Melloh, R. A., and Davis, R. A.: View angle effects on MODIS snow mapping in forests, Remote Sens. Environ., 118, 50-59, 2012. 